\title{
Development of a Scale to Investigate Cybervictimization among Online Social Utility Members
}

\author{
Yavuz Akbulut \\ Yusuf Levent Sahin \\ Bahadir Eristi \\ Anadolu University, Turkey
}

\begin{abstract}
This study aimed to develop a scale to investigate cybervictimization among the members of an online social utility. Eight hundred ninety-six participants were recruited with a 36item web-based survey, which was developed through literature review and expert opinions. The dataset was used for an exploratory factor analysis. After dysfunctional items were eliminated, a 28-item set emerged with a very high internal consistency coefficient explaining half of the total variance with a single-factor structure. The second administration was realized with 200 new participants to confirm the single-factor structure. Along with acceptable fit indices, higher values of internal consistency coefficient and explained variance were observed. It was confirmed that different forms of cyberbullying identified in the literature were included in the questionnaire such as flaming, harassment, cyberstalking, denigration, masquerade, outing and trickery, and exclusion. Receiving religious or politic messages, and unwanted behaviors specifically directed at participants were within the factor structure of the scale. When unwanted behaviors were directed at a larger set of audience, or when the exact target was not the users themselves, such behaviors were not within the factor structure even though somebody else was mistreated. Preliminary findings were discussed followed by implications and suggestions for further research.
\end{abstract}

Keywords: Cyberbullying; online bullying; electronic harassment; cybervictimization; online communication tools; factor analysis.

\section{Introduction}

Information and communication technologies (ICTs) have considerably transformed the lives of learners including the ways they bully each other (Beale \& Hall, 2007). Technology users are now able to select from a variety of effective communication tools to bully one another such as e-mails, instant messaging programs, personal profile Web sites, voting booths, and chat rooms. As the developments in the ICTs are quite dynamic in nature, the nature of bullying occurring through ICT tools (i.e. cyberbullying) should be understood and investigated constantly to propose relevant and timely actions. Hundreds of studies have been conducted addressing 'bullying'; however, a quick search in the ERIC database through the terms 'cyberbullying', 'technobullying', 'electronic bullying', or 'online bullying' finds only a few articles on the matter. In this regard, McLestesr (2008) considers cyberbullying among the top 10 tech trends while examining the major issues, products, and practices of the day regarding contemporary technology and learning. 
Bullying can be defined as intentional and aggressive behavior involving an imbalance of power and strength (Kowalski, Limber, \& Agatston, 2008). After reviewing bullying definitions from the literature, Lee (2004) maintains that six key concepts are covered in most definitions: Intent (deliberate, willful, conscious action), hurt (causes pain, stress, fright, upset or loneliness), repetition (occurs more than once), duration (occurs over a period of time), power (attempts to create pressure and gain strength), and provocation (called forth, invited). McGrath (2007) distinguishes three types of bullying: physical, emotional and relational. Physical bullying involves harm to other individuals' persons or properties. Emotional bullying involves harm to others' self-concepts. Finally, relational bullying involves 'harm to another through damage (or the threat of damage) to relationship or to feelings of acceptance, friendship, or group inclusion' (p.6). Samples of physical bullying can be hair pulling, spitting, biting, punching, extortion, sexual assault, arson and rape, which are somewhat impossible through ICTs for the time being. However, the other two types of bullying may lead to physical inconveniences in the victims. Some of the emotional bullying samples can be listed as dirty looks, name calling, discriminating epithets, insulting remarks, harassing or frightening phone calls, challenging in public or unwanted sexually suggestive remarks, images or gestures. Finally, the followings can be listed as examples of relational bullying: Gossiping, starting and spreading rumors, insulting publicly, ruining a reputation, ignoring someone to punish or coerce, exclusion and arranging public humiliation. As the examples provided here from the McGrath (2007) study reveal, bullying through communication technologies are generally of emotional and relational types.

Emerging ICT tools with higher levels of interaction and influence on individuals' lives require scholars to expand the traditional definition of bullying to the borderless digital world, where non-physical aggression is often observed not only among adolescents but also among other social utility users in different age groups. Several definitions of cyberbullying can be found in the literature. In the current study, it is defined through resorting to several current resources (Anderson \& Sturm, 2007; Chibbaro, 2007; Diamanduros, Downs, \& Jenkins, 2008; Kowalski et al., 2008) as using ICTs to support intentional, recurrent and mean-spirited actions with the aim of harming others. Willard (2005) considers cyberbullying as sending or posting harmful or cruel contents using the digital communication devices. She further classifies the ways in which cyberbullying may occur: Flaming involves sending angry, rude or vulgar messages directed at individual(s) privately or to online groups. Harassment refers to sending a person offensive messages repeatedly. Cyberstalking means harassment with threats of harm or is highly intimidating. Denigration refers to posting harmful, untrue or cruel statements about other people. Masquerade involves pretending to be someone else and sending material to make that person look bad, or get into trouble. Outing and Trickery refer to sending or posting material that contains private or embarrassing information about a person, engaging in tricks to solicit embarrassing information to make that information public, and forwarding private messages and images. Finally, exclusion refers to actions that intentionally exclude a person from an online group.

As implied in several definitions of the construct, harm is intended in bullying behaviors. Generally, the perpetrator has more power than the target of bullying and enjoys the bullying acts (McGrath, 2007). The victim is often hurt physically or psychologically. In this regard, cyberbullying disrupts all aspects of learners' lives (Feinberg \& Robey, 2008). Thus, the society is now moving away from the attitude of considering bullying as a natural part of growing up to considering the deep emotional damage bullying can cause (Anderson \& Sturm, 2007). It has been empirically shown that there is a significant relationship between cyberbullying and 
emotional distress (Juvonen \& Gross, 2008; Ybarra, 2004; Ybarra, Mitchell, Wolak, \& Finkelhor, 2006). Moreover, since there is a correlation between perceived psychological vulnerability and student achievement (Nishina, Juvonen, \& Witkow, 2005), cyberbullying seems to interfere particularly with the academic development of learners.

Even though cyberbullying is really hurtful, it is also attractive to Web users particularly because of the anonymity involved in the cyberspace. That is, perpetrators are able to shield themselves through user names that hide their identities (Shariff, 2008). In this regard, cyberspace has provided learners with a new and enormous platform to abuse their peers. As Froese-Germain (2008) maintains, teenagers engage in cyberbullying '...because of the ease with which digital content can be captured and transmitted, as well as a lack of empathy stemming from the fact that perpetrators can't see or hear the impact of their actions on the victim' (p.44).

One of the recent and comprehensive studies regarding bullying experiences in cyberspace has been conducted by Juvonen and Gross (2008), who administered an anonymous Web-based survey to one thousand four hundred 12- to 17-year-old youth representing all 50 states in the USA. Findings revealed that 72 percent of respondents reported at least one online bullying incident, 85 percent of whom also experienced school bullying. Name-calling or insults were the most frequent forms of both online and in-school bullying. In addition, instant messaging was found to be the most prevalent platform for online bullying. Interestingly, it was indicated that repeated school-based bullying experiences increased the likelihood of cyberbullying more than the use of any particular ICT tool. In addition, a considerable number of cyberbullying victims reported to know their perpetrators. Half of the victims knew the perpetrator from the school, which somewhat supported the 'New bottle but old wine' assumption of Li (2007) whose data revealed somewhat similar but less definitive results regarding the connection between online and in-school bullying. Similarly, data from empirical studies revealed that when schoolmates had Internet connection at home, online communication was largely realized within school-based peer networks (Gross, 2004; Livingstone, 2003).

A common finding in both the Li (2007) and the Juvonen and Gross (2008) study is that majority of the cyber-bully victims do not report the incident to adults -digital immigrants- who are not familiar with the ICTs with which bullying instances occur. As they are unfamiliar with the technology, they tend to see online communication tools as unique risky territories for cyberbullying, rather than an extension of school bullying. On the other hand, these studies implied that a considerable amount of variance in the cyberbullying construct could not be explained through school bullying, which attributed some unique characteristics to cyberbullying. Thus, it might be suggested that school bullying and cyberbullying are interrelated constructs both having their own unique characteristics as well.

One of the first studies on cyberbullying among Turkish youth was conducted by Erdur-Baker and Kavşut (2007) with two hundred twenty eight 14- to 19- year-olds to describe the appearances of cyberbullying. Even though the sample was too small and homogeneous to be representative of the Turkish adolescents, findings revealed that cyberbullying was a serious problem among Turkish high school students. Using the data collection tool in the Erdur-Baker and Kavşut (2007) study, Topçu, Erdur-Baker and Çapa-Aydin (2008) examined the nature of cyberbullying experiences among public and private school students. A total of one hundred eighty three 14- to 15-year-olds were administered a questionnaire to address their cyberbullying experiences both as victims and bullies. Even though private school students 
reported to use Internet-mediated communication tools more often in comparison to public school students, public school students were more likely to report being cyberbullies and cybervictims. Findings of the study revealed quite interesting insights regarding the cyberbullying behaviors of teenagers from different socio-economic backgrounds. The logistic regression analyses indicated that usage frequency of online communication tools was a significant predictor of cyberbullying and victimization for public school students rather than for private school students. Participants from private schools did not mind the cyberbullying experience because they thought it was a joke whereas participants from public schools reported to feel angry when faced with cyberbullying. Probably, victims / bullies from different socio-economic backgrounds have different inclinations while locating the thin line at which conversations move from friendly banter to bullying, an issue discussed by Shariff (2004) within the framework of 'teen talk'.

It has been empirically revealed in the Turkish context by Arıcak (2009) that a significant relation between cyberbullying and anonymity exists. Arıcak (2009) administered a questionnaire on cyberbullying and a Symptom Check list-90-Revised From to 695 undergraduate university students to examine the harmful consequences of cyberbullying. The path analysis indicated that hostility and psychoticism predicted cyberbullying at a statistically significant level. Males resorted to online impersonation more frequently than females. Easily maintaining anonymity in cyberspace was found to be one of the triggers of cyberbullying. One of the significant findings revealing the seriousness of the problem in the Turkish context was that nearly half of the participants reported to masquerade on the Internet or cell phone at least once. Since the dataset comes from pre-service teachers from a single state university, findings can be considered as suggestive. However, the study reveals that cyberbullying is not merely an issue of adolescence, but extends to adulthood as a serious matter in the Turkish context.

The current study primarily focused on cybervictimization instances reported by the members of a popular online social utility. In this regard, bullying instances occurring with mobile phones were not within the scope of this study. Moreover, collecting data from participants in formal educational settings was found to be insufficient as some of those participants might not be active Internet users and real cyber-victims. Thus, the data were collected online. Cybervictimization was preferred to cyberbullying, as Internet users would provide more reliable responses when they were asked about cybervictimization. More specifically, since the majority of participants provide their real names as username in the social utility used in this study, items addressing their bullying acts would not help researchers to retrieve reliable responses. Nevertheless, when the extent of cybervictimization is clarified, it might be possible to see the characteristics of victims generally preferred by bullies. In addition, the sample of the current study was not limited to adolescents in contrast to previous comprehensive studies (Juvonen \& Gross, 2008; Smith et al., 2008). The rationale was that cyberbullying is not merely an issue of adolescence, but an issue that may also occur in later ages as shown in the Aricak (2009) study.

In brief, as the amount of Internet-mediated communication tools is increasing rapidly and as cyberbullying is quite attractive to Internet users, it is quite likely that bullying instances will increase in such a limitless and borderless context. That is, more users will be cyber-victims in near future. On the other hand, it is maintained that cyberbullying occurs everywhere and at every age regardless of gender, socioeconomic status and age. One important point to consider is that even though most adult users have the chance to develop personal protection mechanisms against cyberbullying, a considerable number of novice learners are still deprived 
of finding a working solution regarding such improper behaviors. Moreover, novice victims tend to hide such instances from their teachers and parents. What is more relevant to the current study and the applications of educational technology is that cyberbullying interferes with student achievement, which makes it crucial to investigate the extent of cyberbullying among the users of online communication tools.

It might be impossible to control such a harmful behavior in the borderless online world unless timely and effective actions are taken. The first step is to report the types and extent of such instances in the cyberspace through reliable and valid measurement tools so that the construct is measured effectively to be used as a 'reliably measured variable' in further studies. Thus, the particular aim of the current study was to develop a reliable measurement tool to investigate the extent of cybervictimization to be integrated into future research endeavors. The scale built on other tools developed to measure cyberbullying, but primarily focused on cybervictimization instances occurring through online communication tools. In addition, one of the prevalently used scales developed in the Turkish context by Erdur-Baker and Kavşut (2007) did not address cyberbullying instances in online social utilities sufficiently (Erdur-Baker, personal communication, February 3, 2009). Thus, the current study particularly aimed to address the users of online social utilities, and cyberbullying instances occurring through online communication tools. First, an exploratory factor analysis was conducted to see the factor structure of the developed scale (Study I). Then, the scale was administered again to validate the factor structure through a new dataset (Study II).

\section{Study I}

\section{Participants}

Participants were recruited through a popular online social utility which had more than 450.000 active Turkish users per month. Choosing online users as participants helped researchers to access a more focused target population than administering the questionnaire in traditional school settings, where some respondents might not be active Internet users. After four participants responding to the questionnaire with an unreliable pattern were eliminated (e.g. participants marking all items as 5), the number of valid questionnaires was 896. Of this total, 618 (69\%) were males, and 278 (31\%) were females. All educational levels were represented in the dataset. That is, participants from $\mathrm{K}$ through $8(8 \%)$, high schools (41.4\%), colleges (45.2\%), and graduate schools (5.4\%) were available. Participants' demographic information was provided with regard to gender and age in Table 1.

Table 1. Demographics of the participants: First administration

\begin{tabular}{lccccccc}
\hline & \multicolumn{2}{c}{ Male } & \multicolumn{2}{c}{ Female } & \multicolumn{2}{c}{ Total } \\
\hline Age & $\mathrm{n}$ & $\%$ & $\mathrm{n}$ & $\%$ & $\mathrm{n}$ & $\%$ \\
\hline 10 to 15 & 32 & 5,18 & 25 & 8,99 & 57 & 6,36 \\
16 to 20 & 110 & 17,80 & 69 & 24,82 & 179 & 19,98 \\
21 to 25 & 237 & 38,35 & 80 & 28,78 & 317 & 35,38 \\
26 to 30 & 139 & 22,49 & 52 & 18,71 & 191 & 21,32 \\
Over 31 & 100 & 16,18 & 52 & 18,71 & 152 & 16,96 \\
Total & 618 & 100 & 278 & 100 & 896 & 100 \\
\hline
\end{tabular}




\section{Data Collection Tool}

A personal information form followed by 36 Likert items was used to collect data. Likert items were designed to find out about participants' online communication experiences involving cybervictimization. First of all, 59 items addressing cyberbullying instances were prepared by the researchers through an extensive literature review. The studies of Erdur-Baker and Kavşut (2007), Hinduja and Patchin (2008), Juvonen and Gross (2008), Lee (2004), Li (2008) and Willard (2005) were particularly helpful during item development. The items particularly focused on emotional and relational cybervictimization in cyberspace. That is, perpetrators were not sought for. Statements addressing cybervictimization instances like flaming, harassment, cyberstalking, denigration, masquerade, outing and trickery, and exclusion were revised by three Ph.D. students and two instructors at the Department of Computer Education and Instructional Technologies at Anadolu University. During revisions, key concepts that are covered in definitions of cyberbullying were checked as well (Lee, 2004). That is, phrases implying intent, hurt, repetition, duration, power or provocation were used whenever applicable. Items addressing identical constructs were eliminated through expert opinions. Finally, two scholars in the Department of Educational Sciences reviewed the scale. In the end, a total of 36 items were selected for inclusion in the questionnaire. The frequency of cybervictimization instances was investigated on 5-item scales: never, rarely, sometimes, very often, and always referred to $1,2,3,4$, and 5 respectively. The internal reliability obtained from the first implementation was .961 .

\section{Procedure}

The data collection procedure was realized in February 2009. Through a link embedded in the social network application, participants were invited to respond to the questionnaire. To minimize self-selection bias, the term 'bullying' was never used during the administration as done in the Juvonen and Gross (2008) study. They were also told that they could withdraw from the study any time. After the data were collected, exploratory factor analysis was conducted to identify the underlying structure of the scale and to eliminate complex items.

\section{Results}

The suitability of the current data for factor analysis was checked through several criteria. First, 896 participants were found to be sufficient for factor analysis according to several resources (Comrey \& Lee, 1992; Field, 2000; Pallant, 2001; Tabachnick \& Fidell, 1996). Second, the Kaiser-Meyer-Olkin Measure of Sampling Adequacy (KMO) was checked. This value varies between 0 and 1 . A value close to 1 indicates that patterns of correlations are compact, and factor analysis will yield reliable factors. KMO values of .60 or above are acceptable (Pallant, 2001). The KMO value of the initial analysis was .968, which is considered perfect by Hutcheson and Sofroniou (1999). Finally, the Bartlett's Test of Sphericity reached a significant value supporting the factorability of the correlation matrix obtained from the items (Approx. Chi-Square: 19954.29; $p<.001$ ).

The Pearson product-moment bivariate correlation matrix was the matrix of association used in the analysis. The principal component analysis revealed five components with eigenvalues exceeding 1, which explained 61 percent of the total variance. However, 44 percent of the 
total variance was explained by the first factor. Individual contributions of other factors, which included one or two complex items each, were trivial. That is, the eigenvalue of the first factor was 15.78 , whereas the others ranged from 1.1 to 2.6 .

In order to eliminate nonadaptive items, several criteria were taken into account simultaneously. Items were checked for low corrected item-total correlation values. The values ranged between .46 and .71, which were ideal (Pallant, 2001). After eight complex items with very close loadings under different factors were excluded, remaining items explained 48 percent of the total variance with a single-factor structure. The explained variance for different age groups, education levels and gender varied between 46 percent and 55 percent. As the variability explained by the factor structure was expected to be between $40 \%$ and $60 \%$ for an ideal analysis done in social sciences (Dunteman, 1989), 48 percent variance with a single factor was found acceptable. In addition, the explained variance was found to be higher than many single-factor variances reported in the literature (Henson \& Roberts, 2006). Since a single component was extracted, it was irrelevant to rotate the solution. The internal consistency coefficient of the final solution with 28 items was .96. The coefficients were checked for the levels of different variables to see whether the coefficients were consistent for different groups, all of which revealed ideal values: Gender (males: .960; females: .955), age (ranged from .952 to .964), and education status (ranged from .96 [K-8] to .987 [PhD]).

The highest item loading was .777 whereas the lowest one was .487 . Even the lowest loading in the current analysis was considered fair by Comrey and Lee (1992). As loadings in excess of .71 are considered excellent, .63 very good, .55 good, .45 fair and .32 poor (Comrey \& Lee, 1992; Tabachnick \& Fidell, 1996); two items were fair, two items were good, 11 items were very good, and 13 items were excellent in the current study. Means and standard deviations of items, item-total correlations and item loadings were provided in Table 2.

Table 2. Item Statistics for the First Administration

\begin{tabular}{|c|c|c|c|c|}
\hline Items & Mean & SD & $\begin{array}{l}\text { Item- } \\
\text { total } r\end{array}$ & $\begin{array}{l}\text { Item } \\
\text { loading }\end{array}$ \\
\hline 24. Use of my Webcam images without my consent. & 1,61 & 1,06 & 0,743 & 0,777 \\
\hline $\begin{array}{l}\text { 16. Publication of my personal photographs and videos without my } \\
\text { consent. }\end{array}$ & 1,61 & 1,04 & 0,741 & 0,775 \\
\hline 15. Receiving insulting e-mails or instant messages. & 1,56 & 0,98 & 0,735 & 0,770 \\
\hline $\begin{array}{l}\text { 20. Seeing people speaking on my behalf using my nickname } \\
\text { without my knowledge. }\end{array}$ & 1,72 & 1,10 & 0,74 & 0,767 \\
\hline $\begin{array}{l}\text { 7. Confronting with tricks to get my personal information and } \\
\text { publish it on the Web. }\end{array}$ & 1,68 & 1,10 & 0,722 & 0,755 \\
\hline 14. Suffering from software aiming to get my personal information. & 1,79 & 1,12 & 0,719 & 0,75 \\
\hline $\begin{array}{l}\text { 13. Facing with people using my personal information without my } \\
\text { consent. }\end{array}$ & 1,54 & 0,99 & 0,707 & 0,744 \\
\hline $\begin{array}{l}\text { 8. Publication of my personal information through e-mails or instant } \\
\text { messaging tools without my consent. }\end{array}$ & 1,73 & 1,12 & 0,713 & 0,744 \\
\hline 25. Seeing obscene images while using the Webcam. & 1,70 & 1,08 & 0,706 & 0,735 \\
\hline $\begin{array}{l}\text { 17. Being disturbed by people I do not want to chat with in the } \\
\text { instant messaging programs. }\end{array}$ & 1,91 & 1,14 & 0,698 & 0,723 \\
\hline
\end{tabular}


18. Deception by people who are pretending to be someone else.

\begin{tabular}{|c|c|c|c|c|}
\hline $\begin{array}{l}\text { 27. Being urged to vote for or sign in a religious, politic or sports } \\
\text { group. }\end{array}$ & 1,87 & 1,19 & 0,694 & 0,716 \\
\hline $\begin{array}{l}\text { 6. Having problems because my personal information is shared } \\
\text { online without my consent. }\end{array}$ & 1,53 & 0,95 & 0,675 & 0,711 \\
\hline 12. Receiving threatening e-mails or instant messages. & 1,45 & 0,90 & 0,667 & 0,708 \\
\hline 21. Receiving obscene e-mails. & 1,97 & 1,22 & 0,685 & 0,704 \\
\hline 10. Being blocked by others in instant messaging programs. & 1,72 & 1,05 & 0,673 & 0,700 \\
\hline $\begin{array}{l}\text { 22. Receiving unwanted content to my personal computer without } \\
\text { my consent. }\end{array}$ & 1,96 & 1,21 & 0,677 & 0,696 \\
\hline $\begin{array}{l}\text { 19. Losing my passwords or being obliged to change them because } \\
\text { of password thieves. }\end{array}$ & 1,95 & 1,25 & 0,664 & 0,692 \\
\hline 5. Seeing incorrect and mean-spirited things written about me. & 1,68 & 1,03 & 0,655 & 0,688 \\
\hline $\begin{array}{l}\text { 26. Receiving proposals with sexual allusion from people I know / I } \\
\text { do not know. }\end{array}$ & 1,92 & 1,18 & 0,65 & 0,676 \\
\hline $\begin{array}{l}\text { 4. Receiving instant messages or e-mails including incorrect or bad } \\
\text { things about my friends. }\end{array}$ & 1,66 & 0,98 & 0,636 & 0,668 \\
\hline $\begin{array}{l}\text { 23. Facing with cursing or slang language while using instant } \\
\text { messaging programs. }\end{array}$ & 2,29 & 1,27 & 0,634 & 0,653 \\
\hline $\begin{array}{l}\text { 28. Confronting with people hiding their identities while } \\
\text { communicating with me. }\end{array}$ & 2,31 & 1,36 & 0,622 & 0,641 \\
\hline $\begin{array}{l}\text { 11. Receiving messages with religious or politic content without my } \\
\text { consent. }\end{array}$ & 2,00 & 1,20 & 0,616 & 0,640 \\
\hline $\begin{array}{l}\text { 9. Being specifically and intentionally excluded from an online group } \\
\text { / chat room. }\end{array}$ & 1,76 & 1,11 & 0,601 & 0,629 \\
\hline $\begin{array}{l}\text { 2. Being mocked in online social utilities because of my physical } \\
\text { appearance, my character or an instance I experienced. }\end{array}$ & 1,61 & 0,97 & 0,577 & 0,608 \\
\hline $\begin{array}{l}\text { 3. Being invited to social applications including gossips or } \\
\text { inappropriate chat. }\end{array}$ & 2,26 & 1,25 & 0,505 & 0,527 \\
\hline 1. Receiving harassing e-mails or instant messages. & 1,88 & 1,05 & 0,465 & 0,487 \\
\hline
\end{tabular}

$N=896$

\section{Study II}

Refining the factor structure of a scale using both exploratory and confirmatory analyses is appreciated by the scholars in the field of educational and psychological measurement. However, it is imperative the final model fit be validated by a new dataset to sustain outside confirmation. That is, the confirmation of the current factor structure should be realized through structural equation modeling after the collection of additional data from a similar sample (Henson \& Roberts, 2006). In this regard, the confirmatory factor analysis reported below aimed to validate the factor structure observed in the first administration.

\section{Participants}

Similar to the previous administration, participants were recruited through the same online social utility. Participants who responded to the first version of the scale were not included in 
the confirmation group. First of all, six participants, responding to the questionnaire with an unreliable pattern, were excluded from the dataset. The number of valid questionnaires was 200 after this elimination. Of this number, 134 (67\%) were males, and 66 (34 \%) were females. Table 3 provided participants' demographic information with regard to age and gender.

Table 3. Demographics of the Participants: Second Administration

\begin{tabular}{lcccccc}
\hline & \multicolumn{2}{c}{ Male } & \multicolumn{2}{c}{ Female } & \multicolumn{2}{c}{ Total } \\
\hline Age & $\mathrm{n}$ & $\%$ & $\mathrm{n}$ & $\%$ & $\mathrm{n}$ & $\%$ \\
\hline 10 to 17 & 25 & 18,66 & 17 & 25,76 & 42 & 21 \\
18 to 25 & 60 & 44,78 & 27 & 40,91 & 87 & 43,5 \\
26 to 33 & 34 & 25,37 & 17 & 25,76 & 51 & 25,5 \\
34 to 41 & 12 & 8,96 & 3 & 4,55 & 15 & 7,5 \\
Over 42 & 3 & 2,24 & 2 & 3,03 & 5 & 2,5 \\
Total & 134 & 100 & 66 & 100 & 200 & 100 \\
\hline
\end{tabular}

\section{Procedure}

The 28-item data collection tool developed after the first implementation was used to retrieve participant responses. The second administration was realized to corroborate the underlying structure of the scale through confirmatory factor analysis. Participant recruitment was realized through the online social utility application again in February 2009. In order to sustain a robust confirmation, participants who contributed to the first administration were not allowed to respond to the second version. Besides that, the data collection procedures were identical to the procedures followed in Study I.

\section{Results}

Through LISREL 8.51 for Windows (Jöreskog \& Sörbom, 2001), a confirmatory factor analysis was conducted to test the single factor structure proposed in the previous analysis. The solution with a single latent variable explained by 28 items was examined. The chi-square value $\left(\chi^{2}\right)$ of 747.65 with the corresponding $\mathrm{df}$ of 350 revealed a $\mathrm{df} / \chi^{2}$ ratio of 2.14 which indicated an ideal goodness of fit (Sümer, 2000). In addition to the chi-square goodness of fit, several other fit indices were investigated, which revealed ideal values. More specifically, nonnormed fit index (NNFI: 0.91), comparative fit index (CFI: 0.91) and incremental fit index (IFI: 0.91 ) values were checked. Particularly, the CFI is considered to show a good fit when it is .90 or higher (Bentler, 1995). The goodness of fit index (GFI) was .82 which could be considered lower than the ideal value suggested in the literature (Sümer, 2000); however, the current study was considered as a model development endeavor where a developed scale was administered for the first time. In this regard, the GFI value was considered plausible. Finally, the root mean square error of approximation (RMSEA) was .076 which represented a reasonable fit (Browne \& Cudeck, 1993; Sümer, 2000). It was possible to increase the fit indices and reduce the RMSEA value to better levels through deleting three or four items; however, those items were considered significant for the cybervictimization construct, and the current values were regarded as acceptable. It should also be noted that the single-factor structure in the final administration explained 55 percent of the total variance and had a high internal consistency coefficient $(\alpha=.97)$. The explained variance varied between 49 percent to 
61 percent, and the internal consistency coefficients varied between .96 and .98 for different levels of the background variables (i.e. gender, age and education level). Item statistics for the second administration were provided in Table 4:

Table 4. Item Statistics for the Second Administration

\begin{tabular}{|c|c|c|c|c|c|}
\hline Item & Mean & SD & t value & $\begin{array}{l}\text { Stndrzd } \\
\text { Solution }\end{array}$ & $\begin{array}{c}\text { Error } \\
\text { Variance }\end{array}$ \\
\hline 1. Receiving harassing e-mails or instant messages. & 1,92 & 1,15 & 9,41 & 0,61 & 0,63 \\
\hline $\begin{array}{l}\text { 2. Being mocked in online social utilities because of my physical } \\
\text { appearance, my character or an instance I experienced. }\end{array}$ & 1,81 & 1,06 & 10,26 & 0,65 & 0,57 \\
\hline $\begin{array}{l}\text { 3. Being invited to social applications including gossips or } \\
\text { inappropriate chat. }\end{array}$ & 2,17 & 1,22 & 9,66 & 0,62 & 0,61 \\
\hline $\begin{array}{l}\text { 4. Receiving instant messages or e-mails including incorrect or bad } \\
\text { things about my friends. }\end{array}$ & 1,99 & 1,27 & 10,76 & 0,68 & 0,54 \\
\hline 5. Seeing incorrect and mean-spirited things written about me. & 1,89 & 1,3 & 12,74 & 0,77 & 0,41 \\
\hline $\begin{array}{l}\text { 6. Having problems because my personal information is shared } \\
\text { online without my consent. }\end{array}$ & 1,62 & 1,09 & 12,86 & 0,77 & 0,4 \\
\hline $\begin{array}{l}\text { 7. Confronting with tricks to get my personal information and publish } \\
\text { it on the Web. }\end{array}$ & 1,78 & 1,14 & 13,07 & 0,78 & 0,39 \\
\hline $\begin{array}{l}\text { 8. Publication of my personal information through e-mails or instant } \\
\text { messaging tools without my consent. }\end{array}$ & 1,74 & 1,13 & 12,26 & 0,75 & 0,44 \\
\hline $\begin{array}{l}\text { 9. Being specifically and intentionally excluded from an online group } \\
\text { / chat room. }\end{array}$ & 1,92 & 1,2 & 10,06 & 0,64 & 0,59 \\
\hline 10. Being blocked by others in instant messaging programs. & 1,9 & 1,21 & 11,77 & 0,72 & 0,48 \\
\hline $\begin{array}{l}\text { 11. Receiving messages with religious or politic content without my } \\
\text { consent. }\end{array}$ & 2,09 & 1,31 & 9,68 & 0,62 & 0,61 \\
\hline 12. Receiving threatening e-mails or instant messages. & 1,66 & 1,08 & 13,34 & 0,79 & 0,37 \\
\hline $\begin{array}{l}\text { 13. Facing with people using my personal information without my } \\
\text { consent. }\end{array}$ & 1,75 & 1,21 & 14,07 & 0,82 & 0,33 \\
\hline 14. Suffering from software aiming to get my personal information. & 1,96 & 1,27 & 12,63 & 0,76 & 0,42 \\
\hline 15. Receiving insulting e-mails or instant messages. & 1,81 & 1,17 & 13,37 & 0,79 & 0,37 \\
\hline $\begin{array}{l}\text { 16. Publication of my personal photographs and videos without my } \\
\text { consent. }\end{array}$ & 1,69 & 1,1 & 13,16 & 0,78 & 0,39 \\
\hline $\begin{array}{l}\text { 17. Being disturbed by people I do not want to chat with in the } \\
\text { instant messaging programs. }\end{array}$ & 1,82 & 1,16 & 10,27 & 0,65 & 0,57 \\
\hline 18. Deception by people who are pretending to be someone else. & 1,86 & 1,16 & 12,17 & 0,74 & 0,45 \\
\hline $\begin{array}{l}\text { 19. Losing my passwords or being obliged to change them because } \\
\text { of password thieves. }\end{array}$ & 2 & 1,28 & 11,93 & 0,73 & 0,47 \\
\hline $\begin{array}{l}\text { 20. Seeing people speaking on my behalf using my nickname without } \\
\text { my knowledge. }\end{array}$ & 1,83 & 1,24 & 12,84 & 0,77 & 0,41 \\
\hline 21. Receiving obscene e-mails. & 2,03 & 1,31 & 11,85 & 0,73 & 0,47 \\
\hline $\begin{array}{l}\text { 22. Receiving unwanted content to my personal computer without } \\
\text { my consent. }\end{array}$ & 1,99 & 1,21 & 12,22 & 0,74 & 0,45 \\
\hline $\begin{array}{l}\text { 23. Facing with cursing or slang language while using instant } \\
\text { messaging programs. }\end{array}$ & 2,21 & 1,23 & 10,07 & 0,64 & 0,59 \\
\hline 24. Use of my Webcam images without my consent. & 1,66 & 1,14 & 12,54 & 0,76 & 0,43 \\
\hline 25. Seeing obscene images while using the Webcam. & 1,78 & 1,2 & 12,27 & 0,75 & 0,44 \\
\hline $\begin{array}{l}\text { 26. Receiving proposals with sexual allusion from people I know / I } \\
\text { do not know. }\end{array}$ & 1,89 & 1,16 & 10,74 & 0,68 & 0,54 \\
\hline $\begin{array}{l}\text { 27. Being urged to vote for or sign in a religious, politic or sports } \\
\text { group. }\end{array}$ & 1,82 & 1,16 & 11,61 & 0,72 & 0,49 \\
\hline $\begin{array}{l}\text { 28. Confronting with people hiding their identities while } \\
\text { communicating with me. }\end{array}$ & 2,07 & 1,3 & 10,47 & 0,66 & 0,56 \\
\hline
\end{tabular}




\section{Discussion and Conclusion}

Excluded items relatively had higher means than other cybervictimization instances. That is, participants had more problems regarding those items. Seeing obscene scenes and pop-ups; receiving obscene spam mails, advertisements and virus messages from unknown senders; and being invited to Web sites that mock, antagonize, or harass people were excluded from the scale. One of the common characteristics of these items was that they were not specifically 'directed at a person'; a notion addressed in the Willard (2005) classification of cyberbullying. Users tended to consider unwanted behaviors specifically directed at themselves or their friends as cyberbullying. Obscene scenes or symbols confronted in Web pages, obscene popups, spam mails, and propagandas were not within the factor structure of cybervictimization, probably because the participants thought that the sender did not targeted themselves but addressed a larger and ambiguous set of audience. This argument was somewhat supported by the items included in the scale. For instance, participants did not consider obscene messages and contents as cyberbullying when it was regarded as spam. However, they considered such contents as cyberbullying, when these were directed specifically at themselves through e-mails and instant messages. Probably, the prevalence or commonness of unwanted contents deteriorated the perception of cybervictimization. Internet users are now used to see obscene scenes in even serious news pages. Such a routine transforms the way they perceive cyberbullying. Facing with obscene contents everywhere is somewhat a learnt helplessness or insensitivity which is regarded different from other instances of cybervictimization. Similarly, confronting with unwanted content and cursing in forums or chat rooms was excluded from the scale. Probably, such problems are not considered as bullying unless the target is the user, even though somebody else is mistreated.

Receiving romantic friendship offers from the opposite sex was excluded from the factor structure even though the offer comes from unknown senders. This was considered normal as one of the purposes of online communication tools is to build new friendships. However, the thin line differentiating bullying acts from romantic friendship offers was created by the content of the offer. That is, if the offer involved a sexual allusion, the act became bullying. This finding can be peculiar to the Turkish context where conservative behaviors and social acceptance carry relatively more importance. The factor structure may be different in more liberal peer networks, which should be further investigated.

When the Willard (2005) classification was considered, it was observed that all types of cyberbullying she identified were addressed in the current scale. More specifically, flaming (item 15 and 23), harassment $(1,17)$, cyberstalking $(12)$, denigration $(4,5)$, masquerade $(13$, $18,20$, and 28$)$, outing and trickery $(2,6,7,8,14,16,19$, and 24$)$ and exclusion $(9,10)$ were all addressed. In addition, receiving messages with religious or politic content and being urged to support a religious, politic or sports group were within the factor structure. Whether such religious and politic acts are harassment or cyberstalking might differ based on the characteristics of the culture, and the extent of fanaticism assumed by cyber-bullies. Religious and politic content may even be a new form of cyberbullying, if further studies specifically focus on the sub-components to better differentiate the constructs. The current scale had a single factor structure, which prevented researchers from differentiating the items merging into specific sub-components.

Items that had higher means than others in both administrations were similar. That is, being invited to social applications including gossips or inappropriate chat (item 3), receiving 
messages with religious or politic content without user consent (item 11), facing with cursing or slang language while using instant messaging programs (item 23) and confronting with people hiding their identities while communicating with users (item 28) had higher means. Items had considerably different frequency distributions with regard to each other but similar distributions in both administrations. Positively skewed distributions in both implementations might not lead one to despair regarding the extent of cyberbullying among online social utility users. However, a deeper look into the dataset revealed that the amount of participants indicating that a given statement never occurred to them ranged between 20 and 70 percent. This finding is considered interesting and somewhat serious, since even the least prevalent type of cyberbullying was experienced by at least 30 percent of the participants.

Confirmatory factor analysis conducted as the second study revealed acceptable fit indices. However, it was possible to obtain perfect values regarding explained variance, RMSEA and goodness of fit indices through deleting three or four items, since confirming a single-factor structure with too many indicators is not a common incident. Those items were considered necessary for the underlying construct. Moreover, as the literature indicated that observed fit indices were above the acceptable criteria, such a path was not followed. Improvements in the wording of the items without restricting the content of the scale can lead to better fit indices in subsequent administrations.

The average score of 28 items developed in the current study can be used as the dependent variable of further studies to investigate the influence of different background variables on cybervictimization, or as the independent variable of further studies to investigate the influence of cybervictimization on student achievement in distributed learning environments. We have collected data from different populations to investigate the influence of some background variables on cybervictimization. In all administrations, internal consistency coefficients were between .95 and .97 , and the total variance explained by a single factor was at least 45 percent. However, further studies administering the scale in an international context are still needed, since some of the items included in the factor structure of the current scale could be culture-specific. Moreover, the items given in the current study were translations of the original items administered in Turkish. They may work differently in different cultures, since meaning loss might have occurred during translation. In this regard, meticulous single- and back-translation methods should be adopted through subsequent piloting before initiating large-scale international administrations. Adding culture specific items to the scale in different cultures might also work well to explain higher variance. A parallel form of the current victimization scale could also be prepared to address cyberbullying in particular, if researchers had a chance to retrieve more reliable and sincere responses by ensuring that the data are collected anonymously.

Online communication tools have began to serve as indispensable components of hybrid or distributed learning endeavors. Higher levels of interaction sustained by emerging communication tools help us to generate learning environments effectively serving as supplementary or sometimes alternative to classroom instruction on the one hand, but require us to expand the traditional definitions of bullying to the borderless digital world. Triggered with the anonymity involved in the cyberspace along with the lack of empathy stemming from the fact that perpetrators cannot really observe the results of their actions on the victims, cyberbullying seems more common among and more attractive to Web users. As the existence and commonness of the construct are indisputable along with its interference with student achievement, it seems necessary to integrate the variable of cybervictimization 
as a contaminant to the learning outcomes of instructional technology applications, which make use of online social utilities.

\section{References}

Anderson, T. \& Sturm, B. (2007). Cyberbullying: From Playground to Computer. Young Adult Library Services, 5(2), 24-27.

Aricak, O. T. (2009). Psychiatric symptomatology as a predictor of cyberbullying among university students. Egitim Arastirmalari-Eurasian Journal of Educational Research, 34, 167-184.

Beale, A.V. \& Hall, K.R. (2007). Cyberbullying: What school administrators (and parents) can do. The Clearing House, 81(1), 8-12.

Bentler, P. M. (1995). EQS structural equations program manual. Encino, CA: Multivariate Software, Inc.

Browne, M. W., \& Cudeck, R. (1993). "Alternative ways of assessing model fit". In K. A. Bollen \& J. S. Long (Eds), Testing structural equation models (pp.136-162). Newbury Park, CA: Sage Publications.

Comrey, A. L. \& Lee, H. B. (1992). A first course in factor analysis $\left(2^{\text {nd }}\right.$ edition). Hillsdale, NJ: Lawrence Erlbaum Associates, Publishers.

Diamanduros, T., Downs, E., \& Jenkins, S. J. (2008). The role of school psychologists in the assessment, prevention, and intervention of cyberbullying. Psychology in the Schools, 45(8), 693-704.

Dunteman, G. H. (1989). Principal component analysis. Quantitative applications in the social sciences series (vol. 69). housand Oaks, CA: Sage.

Erdur-Baker, O., \& Kavşut, F. (2007). Cyber bullying: a new face of peer bullying. Egitim Arastirmalari-Eurasian Journal of Educational Research, 27, 31-42.

Feinberg, T., \& Robey, N. (2008). Cyberbullying. Principal Leadership, 9 (1), 10-14.

Field, A. (2000). Discovering statistics using SPSS for windows. London: Sage Publications.

Froese-Germain, B. (2008). Bullying gets digital shot-in-the-arm. Education Canada, 48 (4) 4447.

Gross, E. F. (2004). Adolescent Internet use: What we expect, what teens report. Journal of Applied Developmental Psychology, 25 (6), 633-649.

Hinduja, S., \& Patchin, J. (2008). Bullying beyond the schoolyard: preventing and responding to cyberbullying. Thousand Oaks, CA: Corwin Press.

Hutcheson, G., \& Sofroniou, N. (1999). The multivariate social scientist. London: Sage.

Jöreskog, K. G., \& Sörbom, D. (2001). LISREL 8.51. Chicago, IL: Scientific Software, Inc.

Juvonen, J., \& Gross, E. F. (2008). Extending the school grounds?-Bullying experiences in cyberspace. Journal of School Health, 78 (9), 496-505.

Kowalski R. M., Limber, S. P., \& Agatston, P. W. (2008). Cyberbullying: Bullying in the Digital Age. Malden, MA: Blackwell Publishing. 
Lee, C. (2004). Preventing bullying in schools: A guide for teachers and other professionals. London: Paul Chapman Publishing.

$\mathrm{Li}, \mathrm{Q}$. (2007). New bottle but old wine: a research of cyberbullying in schools. Computers in Human Behavior, 23 (4), 1777-1791.

$\mathrm{Li}, \mathrm{Q}$. (2008). A cross-cultural comparison of adolescents' experience related to cyberbullying. Educational Research, 50 (3), 223-234.

Livingstone, S. (2003). Children use of the Internet: reflections on the emerging research agenda. New Media and Society, 5(2), 147-166

McGrath, M. J. (2007). School bullying: Tools for avoiding harm and liability. Thousand Oaks, CA: Corwin Press.

McLestesr, S. (2008). Top 10 tech trends. Technology \& Learning, 28 (6), 14-18.

Nishina, A., Juvonen, J., \& Witkow, M. (2005). Sticks and stones may break my bones, but names will make me feel sick: The psychosocial, somatic, and scholastic consequences of peer harassment. Journal of Clinical Child \& Adolescent Psychology, 34 (1), 37-48.

Pallant, J. (2001). SPSS survival manual. Maidenhead, PA: Open University Press.

Shariff, S. (2008). Cyberbullying: Issues and solutions for the school, the classroom and the home. New York: Routledge.

Smith, P. K., Mahdavi, J., Carvalho, M., Fisher, S., Russell, S., \& Tippet, N. (2008). Cyberbullying: its nature and impact in secondary school pupils. Journal of Child Psychology and Psychiatry, 49 (4) 376-385.

Sumer, N. (2000). Yapisal esitlik modelleri: Temel kavramlar ve ornek uygulamalar [Structural equation modeling: basic concepts and applications]. Turk Psikoloji Yazilari, 3(6), 49-74.

Tabachnick, B. G., \& Fidell, L. S. (1996). Using multivariate statistics ( $3^{\text {rd }}$ edition). New York: Harper \& Row.

Topcu, Ç., Erdur-Baker, O., \& Capa-Aydin, Y. (2008). Examination of cyberbullying experiences among Turkish students from different school types. CyberPsychology \& Behavior, 11 (6), 643-648.

Willard, N. (2005). Educator's guide to cyberbullying addressing the harm caused by outline social cruelty. Retrieved February 7, 2009, from http://www.asdk12.org/MiddleLink/AVB/bully_topics/EducatorsGuideCyberbullying.pdf

Ybarra, M. L. (2004). Linkages between depressive symptomatology and Internet harassment among young regular Internet users. CyberPsychology \& Behavior, 7 (2), 247-257.

Ybarra, M. L., Mitchell, K. J., Wolak, J., Finkelhor D. (2006). Examining characteristics and associated distress related to Internet harassment: findings from the second Youth Internet Survey. Pediatrics, 118, 1169-1177.

Correspondence: Yavuz Akbulut, Assistant Professor, Faculty of Education, Anadolu University, Yunus Emre Campus, Eskisehir, 26470, Turkey. 